\title{
Paisajes urbanos insurgentes de la metrópolis mexicana. Consecuencias de la neutralización del espacio público en los conjuntos habitacionales de la periferia
}

\author{
Javier Fernández Posadas \\ Doctorando del Departamento de Proyectos Arquitectónicos, \\ Universidad Politécnica de Valencia. Valencia, España \\ E-mail: jaferpo@upv.es
}

\begin{abstract}
Resumen. A raíz de la llegada del urbanismo moderno a México, a partir de los años treinta del siglo $X X$, se construyeron en la capital una serie de conjuntos $y$ unidades habitacionales influenciados por las ideas funcionalistas de Le Corbusier, la Escuela de Chicago o las propuestas de la ciudad-jardín británica. Experiencias como las de Hannes Meyer, Mario Pani, Luis Ramos o Antonio Serrato, pensadas para la periferia de entonces bajo la lógica del zonning y en el marco de una modernidad posteriormente truncada, constituyen hoy en día una formidable paradoja: absorbidas actualmente en el interior de la gran estructura de la metrópolis, su densidad habitacional, los servicios y espacios públicos que acompañaban cada proyecto y la importancia de la calle como articulador de la colectividad vecinal, emergen como ideales frente al diseño urbano de los suburbios y fraccionamientos que conforman el actual área metropolitana.

En contraposición al espacio público legado por las propuestas de la modernidad, este artículo propone un recorrido por el paisaje urbano de algunos suburbios de la Zona Metropolitana del Valle de México, donde la especulación urbanistica ha construido lugares uniformes, estandarizados y con un espacio público neutralizado. Ante una arquitectura y un urbanismo que no favorecen la vida urbana propia de las ciudades, la ciudadanía que habita estos lugares ha transformado el paisaje urbano impuesto por la lógica de la ciudad dispersa reivindicando, a través de transformaciones insurgentes, la ciudad que les ha sido negada.
\end{abstract}

Palabras clave: Paisaje urbano, espacio público, identidad, vecindario, suburbios, ciudad difusa

\section{Introducción}

El incremento de población urbana mundial experimentado a partir de la segunda mitad del siglo XX ha convertido en un reto de primera magnitud la sostenibilidad de la vida urbana de las grandes ciudades. Si en 1960, solo un 34\% de la población mundial vivía en asentamientos urbanos, en el año 2007 la población urbana superó por primera vez el $50 \%$, alcanzando en la actualidad, el 54\% . Como consecuencia, las ciudades se han visto abocadas a un proceso de urbanización cada vez más rápido que ha transformado los valores asociados a la ciudad tradicional. Aunque el modelo de ciudad compacta ha asumido con más fortaleza la gestión del crecimiento poblacional frente al modelo de ciudad dispersa, el habitante de la ciudad global se enfrenta por igual a una transformación del significado de urbanidad.

La Zona Metropolitana del Valle de México es hoy una enorme conurbación de $7900 \mathrm{~km} 2$ y más de 20 millones de habitantes que se enfrenta hoy a esta realidad. La manera en la que el proceso urbanizador de la metrópolis se ha extendido por el territorio se asemeja 
a aquella imagen de urbanización planetaria planteada por Henri Lefebvre en 1968 en su obra, Le Droit à la ville, que, tal y como advertía, podría suponer un peligro para la vida y la democracia urbana de sus habitantes.

El proceso de metropolitanización de la ZMVM , que comenzó en la década de 1930 con la llegada de grandes masas de población procedentes del medio rural, se consolidó entre 1950 y 1960 (Garza, 2015), pero no dejó de expandirse de manera acelerada hasta la década de 1980. Esto supuso que de las 16 delegaciones de Ciudad de México y los 4 municipios que configuraban el área metropolitana en 1960 , se haya pasado a un tejido urbanizado prácticamente continuo de suburbanizaciones que aglomera a un total de 60 municipios y que atraviesa el Distrito Federal y el Estado de México y que alcanza al Estado de Hidalgo. De esta forma, en la ZMVM ha desaparecido el esquema tradicional de ciudad asociada a una única administración política rodeada de un entorno natural concreto, dando lugar a una infraestructura interestatal que se extiende por el territorio. Esto la convierte en un laboratorio para investigar, no solo la sostenibilidad futura del urbanismo a gran escala, sino también sobre los valores patrimoniales, ciudadanos y paisajísticos de un modelo de ciudad que está obligando a redefinirlos.

\section{El modelo disperso de urbanización en la ZMVM: ¿Una ciudad-simulacro?}

$\mathrm{Al}$ igual que en otros países latinoamericanos, las suburbanizaciones de la ZMVM siguieron el modelo de dispersión urbana de las ciudades estadounidenses de las décadas de 1940 y 1950 conocido como Urban Sprawl. Basándose en el bajo coste del suelo de la periferia de la ciudad, el uso generalizado del automóvil y en el desarrollo de las infraestructuras del transporte, se construyeron urbanizaciones de baja y media densidad de viviendas unifamiliares dispersas y alejadas de la ciudad consolidada a las que se trasladaron amplios sectores de clase media; al mismo tiempo, tuvo lugar una deslocalización de grandes áreas comerciales y de servicios. El resultado fue una degradación de los centros urbanos (Jackson, 1985; Fishman, 1987) y un cambio morfológico sobre el conjunto de la ciudad, asemejándose a un gran archipiélago cuyas "islas" parecían estar condicionadas en su extensión y forma únicamente por los precios del suelo y por la proximidad a las grandes carreteras y autopistas que atraviesan el territorio.

La consolidación del modelo fordista y de la economía globalizada ha hecho que puedan identificarse rasgos comunes de dispersión en ciudades alejadas geográficamente entre sí y con singularidades socioculturales muy diferentes. La presencia de sprawl en los procesos de urbanización de las ciudades mexicanas (Arellano y Roca, 2010; Monkkonen, 2011), constata que este fenómeno urbano no está ya únicamente asociado a sociedades ricas y economías favorables, sino que también afecta a ciudades con una alta polarización socioeconómica. De hecho, la ZMVM es una auténtica postmetrópoli que actúa como una "fábrica de desigualdad" (Soja, 2000): el centro mantiene un estatus privilegiado respecto de los conjuntos de la periferia, donde los habitantes se enfrentan a una mala distribución de servicios públicos e infraestructuras, además de estar sujetos a tiempos y costes de transporte muy elevados al encontrarse alejados de los centros de trabajo.

La baja densidad de vivienda en las suburbanizaciones, la baja proximidad y concentración de las mismas, la discontinuidad, la fragmentación rígida y la pérdida de centralidad de la ciudad consolidada, son algunas de las características dadas por Galster et al. (2001) del urbanismo disperso que podemos encontrar en muchos lugares de la ZMVM. En municipios como Cuautitlán, Coacalco, Tecámac o Ecatepec de Morelos, se observa cómo los nuevos conjuntos habitacionales se conciben dentro de un planeamiento macroespacial sin relación con las tramas consolidadas y cómo existe un fraccionamiento severo del territorio dedicado a la distribución de miles de viviendas estandarizadas.

Estudios como los de Schteingart (1989), Rodríguez y Arriagada (2004) o Sabatini (2006), han señalado cómo esta fragmentación del suelo ha estado acompañada de una división social del espacio en las ciudades latinoamericanas. La presencia en México de 
este fenómeno (Duhau, 2003; Connolly, 2003, 2012; Garcés-Fierros, 2009) ha convertido al urbanismo en un auténtico mecanismo de segregación. En lugares de la ZMVM esto sucede, no solo a través de la dotación de servicios y accesibilidad, más favorable en urbanizaciones de rentas más altas, sino sobre todo a través del propio trazado viario y el acceso restringido a muchas calles de las urbanizaciones, elementos que actúan como barreras físicas que impiden una circulación libre.

De este modo, estos factores han configurado un paisaje urbano caracterizado por la neutralización del espacio público, siendo, en su mayoría, superficial e inefectivo. Incluso en los desarrollos urbanos de interés social el espacio privado se ha privilegiado y las zonas dedicadas a equipamientos, comercios y zonas verdes también se encuentran sectorizadas, imitando el esquema de organización espacial impuesto por el mercado inmobiliario. Esto ha hecho inoperable la capacidad de las calles para actuar como articuladoras de la vida colectiva y ser el escenario de una identidad común, ya que el uso activo del espacio público, práctica esencial para favorecer la participación ciudadana y el encuentro vecinal, se reduce enormemente en estos conjuntos urbanos.

Los estudios antropológicos que han analizado las rápidas transformaciones a las que se somete el paisaje natural y urbano de la ciudad dispersa hablan de la dificultad que encuentra este urbanismo para adquirir significados que proporcionen valores simbólicos y patrimoniales a sus habitantes (Nogué, 2007). Así, en los conjuntos habitacionales de la ZMVM podemos advertir un paisaje urbano en el que predomina la homogeneización y banalización de la arquitectura y el urbanismo, características propias de la ciudad dispersa (Borja, 2007; Nogué, 2008; Sassen, 2007). Como resultado se ha provocado en el habitante un desarraigo territorial que, sumado a una distribución inefectiva de servicios y equipamientos, implica una inevitable disminución de la calidad de vida. En este sentido, miles de habitantes de la ZMVM han visto frustradas sus expectativas de vida en estos espacios (Sánchez y Salazar, 2011) y se han llegado a producir abandonos masivos de viviendas (INEGI, 2010).

\section{La herencia moderna en la antigua periferia}

El proceso de metropolitanización de Ciudad de México significó la desaparición completa de una periferia natural que se delimitaba con claridad, al menos, hasta mediados del siglo XX. De esta forma, los conjuntos habitacionales construidos durante la modernidad en la periferia han quedado absorbidos dentro del proceso urbanizador, integrándose actualmente en una localización más central dentro de la megalópolis. Esto les dota de gran interés urbanístico, ya que se encuentran rodeadas de un modelo de organización espacial y habitacional distinto al propuesto por las teorías del urbanismo moderno, permitiéndonos contrastar su comportamiento con el de una ciudad del futuro que ya ha sido construida. A pesar del fracaso del urbanismo funcionalista, $\mathrm{y}$ teniendo en cuenta la condición poblacional de la urbe, ¿puede la concepción del espacio público de los modelos construidos durante la modernidad aportar ideas, frente a las carencias que presentan los nuevos desarrollos periféricos?

Aunque previamente ya habían surgido algunas propuestas de corte moderno, se podría considerar que el contacto definitivo de México con el urbanismo moderno internacional tiene lugar con dos hitos: por un lado, con el XVI Congreso Internacional de Planificación y Habitación, celebrado en la capital en 1938, y, por otro, con la creación del "Instituto de Planificación y Urbanismo" en 1941, impulsado por el arquitecto José Luis Cuevas y el exdirector de la Bauhaus, Hannes Meyer. Será a partir de entonces cuando empiecen a construirse los primeros conjuntos habitacionales de gran escala basados en las teorías funcionalistas de los CIAM, Le Corbusier y la escuela de Chicago, modelos surgidos del contexto europeo y estadounidense de las primeras décadas del siglo XX que llegaron también a México bajo la idea del Estilo Internacional.

Una de las primeras propuestas radicalmente modernas fue la "Colonia Obrera de Lomas de Becerra", proyectada, en 1943, por Meyer. El arquitecto suizo sintetizaba, bajo el principio 
del Co-op , sus ideas de compromiso social, cooperativismo democrático e igualitarismo radical. El proyecto consistía en seis grandes manzanas distribuidas, al estilo siedlungen alemán, en una superficie de 60 hectáreas. Con un máximo de 2200 viviendas repartidas en edificios de 3 y 4 plantas, se conseguía una densidad habitacional que variaba entre $190 \mathrm{y}$ $416 \mathrm{hab} / \mathrm{ha}$, es decir, 11000 habitantes en una parcela con un área construida del 14\%; el resto del suelo se destinaba a áreas de esparcimiento, jardines y terrenos de huerto para uso vecinal. Aunque finalmente no se construyó, el promotor habría sido el Estado, significando que el concepto de vivienda colectiva ya había entrado en las instituciones públicas mexicanas. Esto daría paso a los edificios multifamiliares y a las unidades habitacionales inspiradas en los edificios en rendent y las unités d'habitation de Le Corbusier.

En este sentido, aún se levanta, 70 años después de su inauguración, la "Unidad Esperanza". Diseñado, en 1948, por Antonio Serrato en la colonia Narvarte. Este proyecto, que se articula dentro de una única manzana de 1.4 hectáreas, fue el primer conjunto de vivienda colectiva en altura de México. Las 200 viviendas con las que cuenta se distribuyen en 10 edificios de 4 plantas y una inferior, dedicada entonces a uso comercial. Pese al mal estado material en el que se encuentra hoy, la plaza central del interior de la manzana y las zonas peatonales que rodean a sus edificios, encarnan todavía con fuerza la importancia dada por el urbanismo moderno, incluso en proyectos modestos, a un espacio público como enlace básico entre vivienda y ciudad.

Pero el ejemplo paradigmático de la aplicación de los principios modernos en los nuevos conjuntos urbanos mexicanos es el "Centro Urbano Presidente Miguel Alemán" diseñado por Mario Pani e inaugurado en 1949. Aunque el Gobierno Federal tenía previsto realizar en este solar de 4 hectáreas, 200 viviendas, Pani propone elevar la cantidad hasta los 1080 departamentos, alcanzando una densidad de 1000 hab/ha basándose en las ideas de Le Corbusier de la supermanzana como una unidad autónoma dentro de la gran ciudad. La distribución se hizo en 6 edificios de 3 niveles y 9 edificios de 13, dando lugar a que la ocupación del terreno no sobrepasara el $25 \%$. De esta forma se liberó una gran cantidad de suelo en favor de zonas verdes, instalaciones, deportivas, y todo un lote de servicios que debían abastecer al conjunto siguiendo las tesis del policentrismo lecorbusiano.

A estas primeras experiencias les siguieron otras propuestas durante la década de 1950 y 1960, tales como el "Centro Urbano Presidente Juárez” (1950-1952) con 960 viviendas, la "Unidad Santa Fe" (1957) con 2199 viviendas, la "Unidad Independencia" (1960) con 2235 viviendas o la "Unidad Habita $\neg$ cional Nonoalco Tlaltelolco" (1962-1964), diseñada para cien mil habitantes; todas ellas concentran altas densidades de vivienda sin detrimento del espacio público y fueron pensadas para regular de manera ordenada, tanto desde el ámbito público como del privado, la demanda habitacional de un área metropolitana que alcanzaba, en 1960, los 5.2 millones de

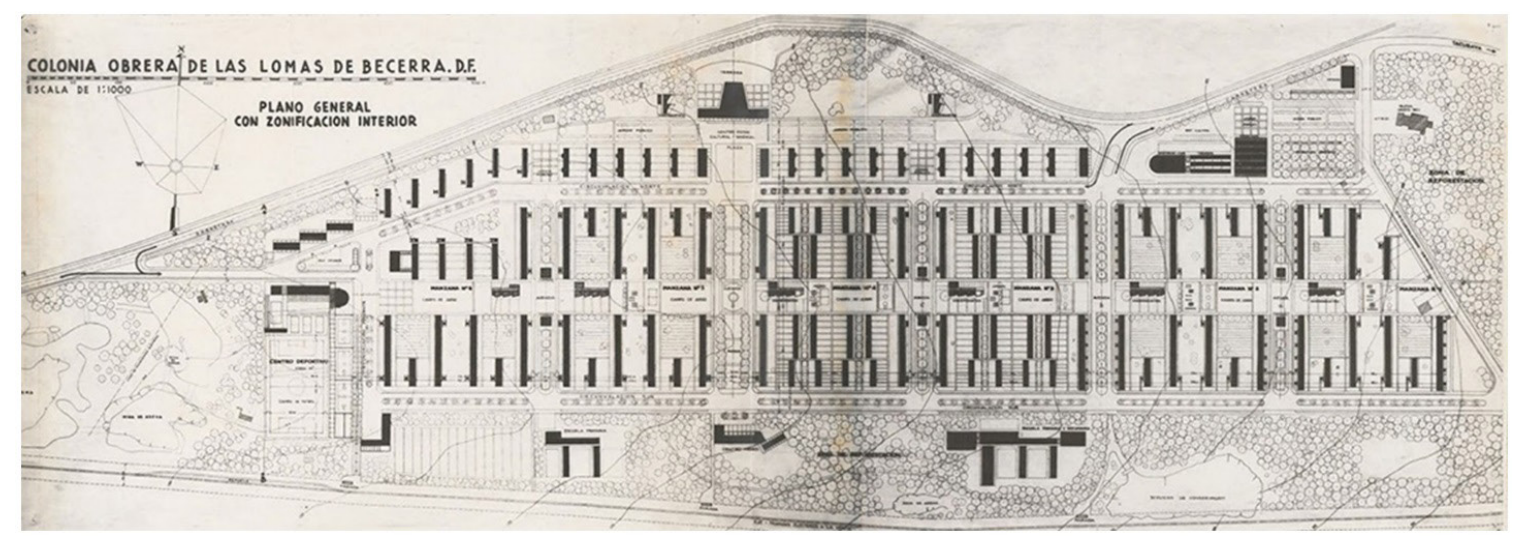

Fig. 1. "Colonia Obrera de Lomas de Becerra". Fuente: AA files, n. 47, Architectural Associaltion, London. p. 58 


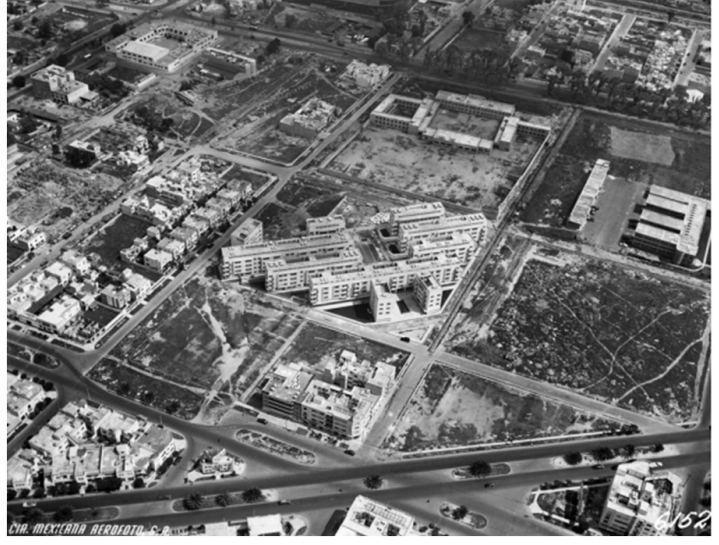

Fig. 2. "Unidad Esperanza". Fuente: Acervo Histórico Fundación ICA, 1948

habitantes y las 951 mil viviendas (Garza, 2015).

Es cierto que la mayoría de estos conjuntos habitacionales sufren problemas técnicos y económicos, y que los servicios que ofrecían, financiados en su mayoría de forma pública, ya no existen. A pesar de esto, sus residentes poseen mejores condiciones de habitabilidad y un espacio público más cercano y efectivo que el que poseen otros habitantes del resto de la ciudad. Esto les ha permitido formarse una identidad vecinal (Garay-Arellano, 2001) garantizándoles, a nivel de espacio existencial, una experiencia de la vida urbana más adecuada que la de muchos desarrollos urbanos periféricos de reciente construcción. Otra de las fuertes críticas que recibieron fue su inadaptabilidad a la sociedad de la época debido a la imposición de nuevos conceptos habitacionales como el apartamento y el edificio en altura. Sin embargo, no deja de ser cierto que el modelo urbano actual no ha propiciado un modelo habitacional basado en el contexto cultural o identitario mexicano, por el contrario, parece haberse aceptado un nuevo "estilo internacional" resultado de la aplicación de las leyes neoliberales del mercado.

\section{El paisaje urbano impuesto}

A la vista de los modelos de expansión actuales, continuar apostando por un espacio público pensado desde la escala doméstica y por la media y alta densidad habitacional en edificios en altura, herencia de la teoría

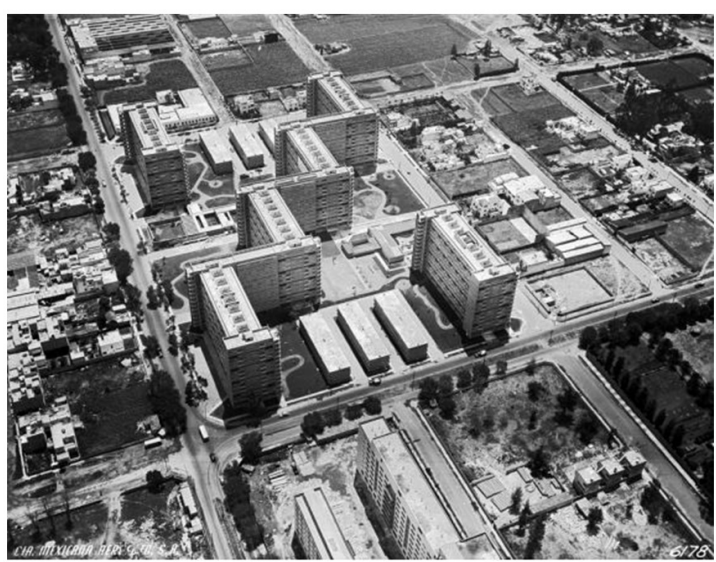

Fig. 3. "Unidad Esperanza". Fuente: Acervo Histórico Fundación ICA, 1948.

del urbanismo moderno, habría conducido a una mayor sostenibilidad de la ciudad actual reformulando las tesis hacia un modelo más compacto de organización espacial. Sin embargo, como indicábamos anteriormente, el resultado de aplicar de forma generalizada el pragmatismo del máximo aprovechamiento económico del suelo del mercado inmobiliario actual, ha conformado en la ZMVM un paisaje urbano caracterizado por su aspecto banal y homogéneo, por su incapacidad para crear un sentido del lugar y por un espacio público neutralizado, asemejándolo a un simulacro de ciudad.

En términos generales, el esquema de desarrollo urbano mexicano de las últimas décadas parte de una unidad de vivienda de superficie construida variable pero estandarizada que se reparte en uno o dos niveles. Distribuidas a lo largo de la calle, imitan el patrón urbanístico del "sueño americano" de adosados unifamiliares con plaza privada de aparcamiento, dando por hecho, desde el planeamiento, el sometimiento insostenible de estos lugares al automóvil. El resultado es la producción seriada de las propias calles que configuran barrios enteros de estructura y organización uniformes.

Además del carácter anónimo de las calles, las zonas verdes, los equipamientos públicos y las zonas comerciales se encuentran concentradas y distribuidas sectorialmente, creando sobre el conjunto una sensación de ciudad-dormitorio. De esta forma, el valor tradicional de la calle y la concepción de espacio público han quedado 


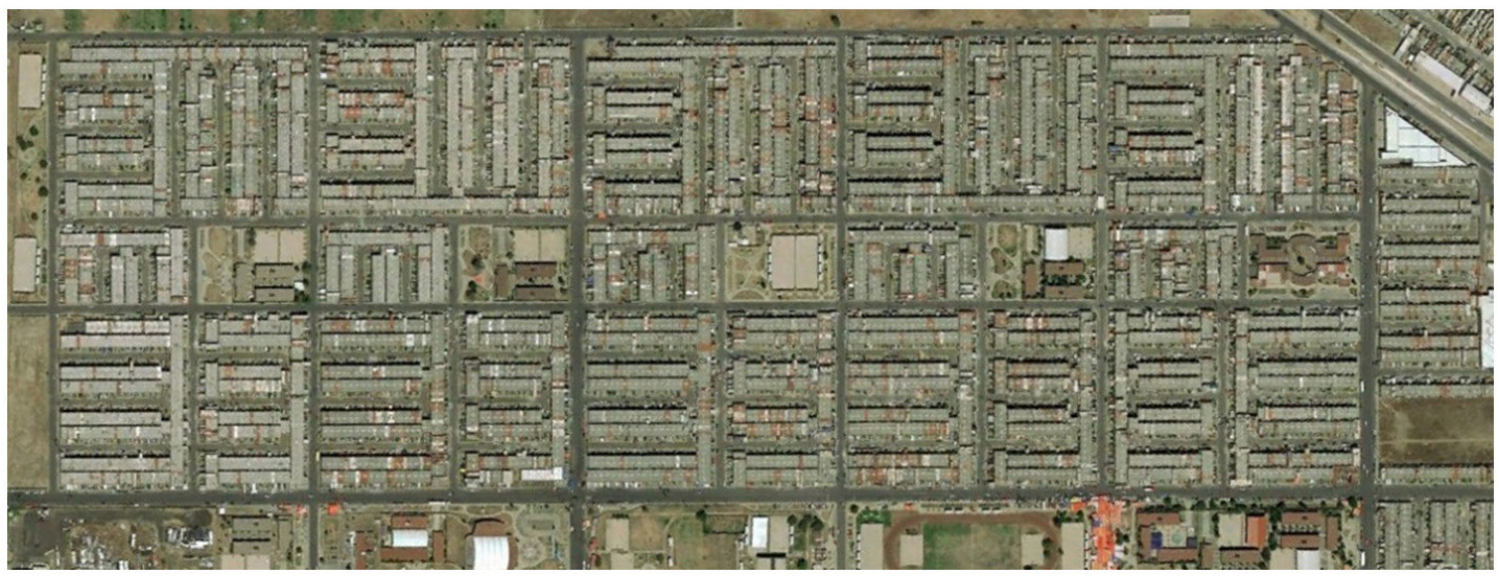

Fig. 4. Banalización y homogeneización urbana. "Los Héroes Tecámac”, Tecámac, México

anulados, ya que, por un lado, la utilidad de la calle ha quedado reducida al acceso a la vivienda y, por otro, la ausencia de locales que puedan adquirirse por parte de los vecinos hace imposible la aparición de comercios de barrio, fomentando más aún la deslocalización del trabajo y la movilidad excesiva. Además, como consecuencia de la inseguridad y el temor a la criminalidad, el mercado inmobiliario vende estas urbanizaciones como un refugio ideal que supuestamente garantiza una vida urbana segura ante los "peligros" de la megalópolis. Así, muchas de ellas son decididamente invisibles, infranqueables en su perímetro y provistas de seguridad privada, fomentando una vida disociada de la comunidad y una visión de la casa como mecanismo de blindaje (Lindón, 2006). De esta forma, además de la pérdida de centralidad y de la reducción en políticas de proximidad, estos factores incrementan la desestructuración social de estos espacios (De Mattos, 2006).

La pérdida del carácter híbrido de las estructuras de organización espacial y de la simplificación del concepto de vivienda digna a una cuestión únicamente de habitabilidad básica interior, ha truncado el valor de la identidad urbana en estos lugares. Esto es constatable en colonias como "Los Héroes Tecámac", "Los Héroes Ozumbilla" o el "Fraccionamiento Verona" construidos en las dos últimas décadas en la periferia del municipio de Tecámac: asentamientos próximos pero sin relación entre ellos, sin diferencias arquitectónicas, sin hitos urbanos, sin monumentalidades simbólicas. Este tratamiento excesivamente uniforme del espacio lo desposee de una identidad que, como diría Marc Augé (1993), impide que puedan definirse como espacios relacionales o históricos. Esto ocurre independientemente de la condición de la vivienda: sectores como "Los Héroes Tecámac I", una entidad de 18340 viviendas unifamiliares de interés social, cuenta con una mejor distribución de zonas de esparcimiento, pero siguen siendo repetitivas $\mathrm{y}$ uniformes, y las calles también han sido diseñadas disfuncionalmente, neutralizando el capital social del asentamiento para hacer ciudad.

\section{El paisaje urbano insurgente}

Tal y como explican Jordi Borja y Zaida Muxí en El espacio público: ciudad y ciudadanía, la importancia del espacio público no radica únicamente en su valor como medidor de calidad urbana sino que es parte esencial para el ejercicio del derecho a la ciudadanía de los habitantes de la ciudad y un asegurador de democracia urbana. Urbanistas

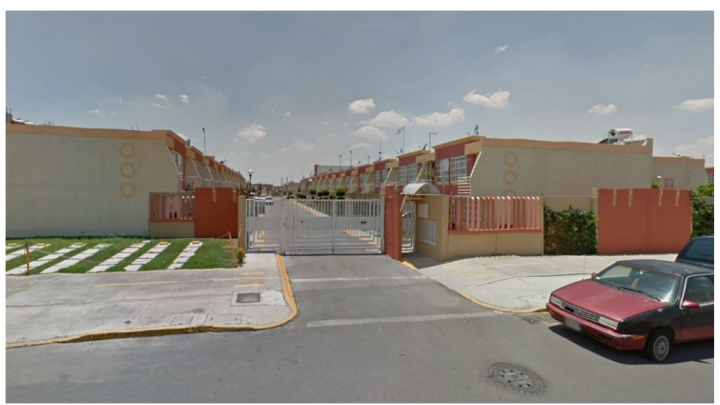

Fig. 5. Calle con acceso restringido. Ojo de Agua, México. 


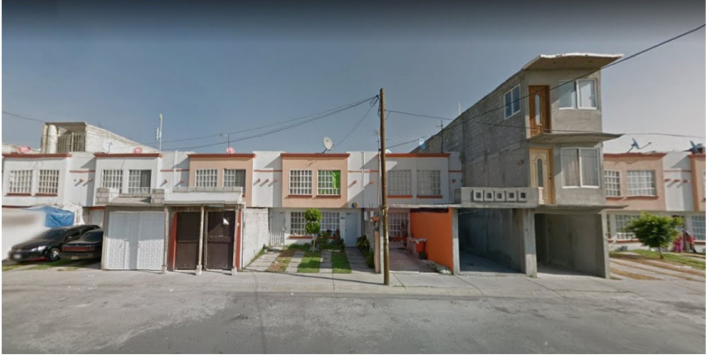

Fig. 6. Tecámac, México.

comprometidos con la función social y el papel para la colectividad de la ciudad como Henri Lefevbre, Jane Jacobs, Manuel Castells, Jordi Borja y tantos otros, han reivindicado desde sus planteamientos intelectuales una actualización en el modo de entender la ciudad contemporánea y un cambio en las políticas que garantice, cada vez más, el derecho a una ciudad segura, saludable y sostenible. Si bien las carencias en materia urbana suelen detectarse por las administraciones a través de las protestas y denuncias vecinales, y a pesar de que la estadística es el método más fiable para evidenciar la realidad social de los barrios, la transformación a la que los habitantes someten el paisaje urbano original construido por la lógica de la dispersión en lugares como la ZMVM, es la señal más inmediata del fracaso que implica su aplicación a una escala tan enorme.

Es frecuente asociar las transformaciones urbanas realizadas por iniciativa de la ciudadanía con factores como la marginalidad, la autoexclusión, o con un supuesto rechazo a los sistemas de organización espacial y habitacional normativos. Sin embargo, la generalización con la que se da sobre espacios tan extensos, no es más que el síntoma de la falta de urbanidad a la que ha conducido su diseñado. A diferencia de la ciudad informal , donde la autoconstrucción es el punto de partida previo y el abastecimiento de servicios y la adquisición de derechos ciudadanos es posterior, en los desarrollos urbanos de la ciudad dispersa mexicana se produce un proceso contradictorio. Estos asentamientos han seguido el proceso de crecimiento urbano propuesto por Manuel Solà-Morales (1997) de parcelación, urbanización y edificación, es decir, la ciudad se ofrece al futuro habitante

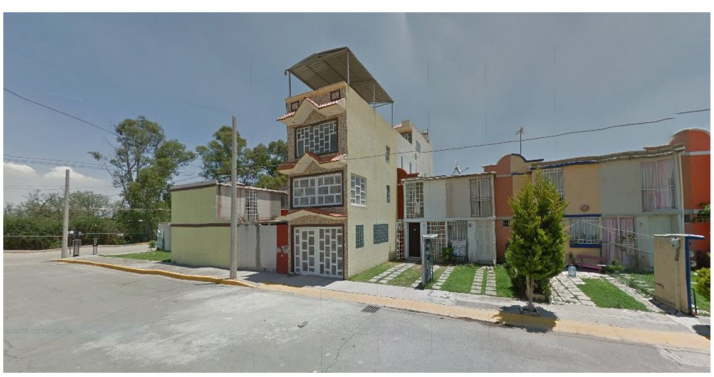

Fig. 7. Cuautitlán, México.

aparentemente completa en forma y contenido pero, sin embargo, una vez habitado tiene lugar un proceso de remodelación interna donde aparece sorpresivamente la autoconstrucción y la informalidad. Así, como respuesta a una planificación urbana que no satisface plenamente los intereses más básicos de su ciudadanía, surge un paisaje urbano caracterizado por su insurgencia.

Bajo esta óptica, las manipulaciones a la que los propietarios someten el estado original de las viviendas se pueden entender como una disconformidad con la homogeneización de la arquitectura que más inmediatamente controlan. La realidad del futuro propietario es la imposición, no solo de un entorno repetitivo e impersonal, sino de un modelo familiar que debe ajustarse a una superficie también estandarizada entre los 3 o 4 prototipos de vivienda disponibles. Así se producen, desde cambios estéticos en la fachada que buscan la personalización del espacio propio, hasta alteraciones radicales mediante la autoconstrucción que muestran la necesidad de sobrepasar la superficie para adaptarla al proyecto vital del habitante. En su mayoría, éstas últimas incumplen el manual de la vivienda que les proporciona el promotor y comprometen en muchos casos la seguridad estructural de las mismas. Esta disconformidad, demuestra que la libertad de elección para elegir una vivienda en estos conjuntos habitacionales no es más que una ilusión que no se corresponde con la realidad social de sus habitantes y que el futuro propietario la acepta sin renunciar a la posibilidad de subvertirla en el futuro.

Otra transformación característica de este paisaje insurgente es la negación del espacio de estacionamiento del automóvil que, como consecuencia de la limitación espacial y de 


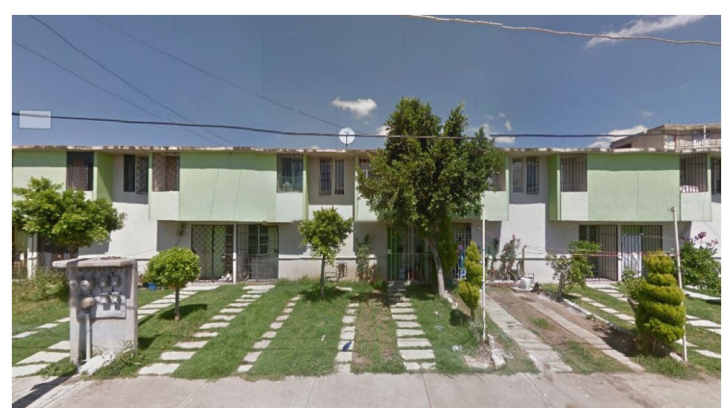

Fig. 8. Cuautitlán, México.

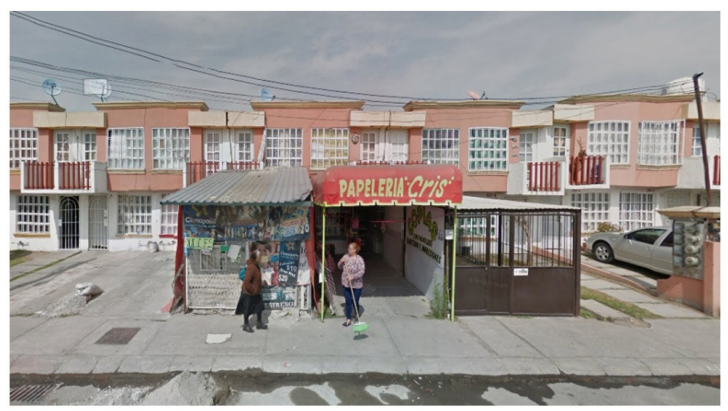

Fig. 9. Tecámac, México.

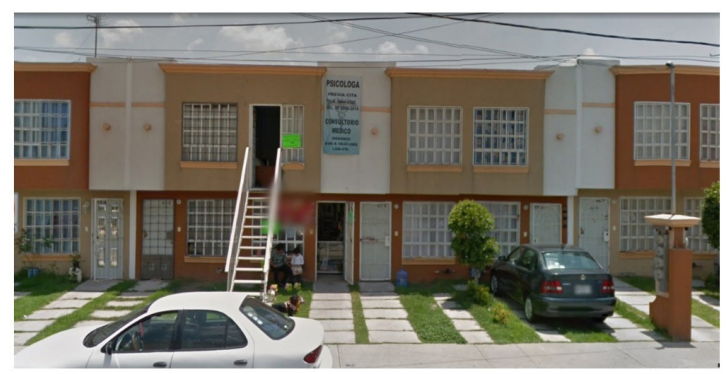

Fig. 10. Tecámac, México.

las expectativas de crecimiento económico o familiar, se aprovecha para construir un nuevo habitáculo que, en ocasiones, puede tener más de un nivel de altura. También es habitual su conversión en almacén, en zona ajardinada o en zona de juego para niños. Esto último revela, no la inutilidad de las zonas destinadas macroespacialmente a estos usos, sino la falta de una distribución de suelo verde y de esparcimiento a una escala más domestica como las plazas y los puntos estratégicos destinados a este fin que habitualmente existen en las ciudades.

Pero la "insurgencia" más característica de este paisaje urbano es el sacrificio de superficie destinada a vivienda para compatibilizarla con el uso comercial y la prestación de servicios. Como hemos explicado, el sometimiento de sus habitantes a centralidades laborales alejadas de estas colonias, condiciona enormemente la búsqueda o el emprendimiento de un trabajo cercano al hogar, de manera que los habitantes se ven obligados a emanciparse de ellas y a abrir sus negocios en el único espacio que pueden adquirir: la vivienda. De esta forma, desempeñan labores profesionales en el interior de sus casas o colocan toldos y quioscos en la zona de estacionamiento del automóvil para ofrecer sus servicios. Es habitual también que muchos vecinos se agrupen en torno a las áreas comerciales definidas sectorialmente y tomen las calles adyacentes formando un mercado de carácter irregular en el que disponen sus tiendas y puestos de venta.

La cotidianidad de estas prácticas poco tiene que ver con la marginación, la autoexclusión o con un deseo de negar las normativas dadas por el conjunto de la sociedad sino que responden a la legítima necesidad de adaptar el hábitat a un lugar dado que no ha sido pensado en términos de espacio existencial. Si tomamos como referencia los derechos ciudadano-urbanos planteados por Jordi Borja y los relacionamos con las transformaciones a las que se somete el paisaje impuesto en la ZMVM, encontramos que éstas son la manera que tienen los habitantes de reivindicar dichos derechos. Algunos de ellos como el derecho a la vivienda y al lugar, al espacio público, a la belleza, a la identidad colectiva, a la movilidad, a la centralidad, a la diferencia, al medioambiente o al empleo, aparecen en las alteraciones que conducen al paisaje urbano insurgente y actúan como indicador de la necesaria renovación de la cultura política y gubernamental de la ciudad y de la urgencia de hacer eficaz la democracia urbana en la ciudad contemporánea tal como propone Borja.

En definitiva, la trasformación del paisaje banal y homogéneo practicado por una amplia masa de población en barrios o colonias que funcionan como simulacro de ciudad, manifiesta la precariedad urbana que se esconde detrás de estos asentamientos. Como explica Manuel Castells en La ciudad y las masas. Sociología de los movimientos sociales urbanos, las formas espaciales se moldean inicialmente de acuerdo a los intereses de una clase dominante que impone también sus 
modelos de producción y de desarrollo; una vez habitadas, aparecen movimientos sociales que contradicen el significado original de la estructura espacial y, a modo de resistencia, lo readaptan a sus realidades e intereses propios a través de nuevas funciones y formas, ya que, citando a Castells, "el espacio no es un reflejo de la sociedad, es su expresión. (...) no es una fotocopia de la sociedad: es la sociedad misma".

\section{Notas}

1 Datos Grupo Banco Mundial. https://datos. bancomundial.org

2 INEGI. Censo de Población y Vivienda 2010. https://www.inegi.org.mx/programas/ ccpv/2010/

3 Siglas de Zona Metropolitana del Valle de México.

4 Estos municipios eran Naucalpan, Tlalnepatla, Ecatepec y Chimalhuacán. Para la delimitación actual de las zonas metropolitanas y los municipios que la componen actualmente puede consultarse la página del Consejo Nacional de Población de México. http://www. conapo.gob.mx

5 Otros autores como Fulton et al. (2001), utilizan el consumo de suelo urbano por habitante como medidor, determinando que existe dispersión cuando la velocidad de consumo de los recursos del suelo es mayor que el crecimiento de población.

$6 \mathrm{Se}$ pueden citar como relevantes la "Colonia Hipódromo" (1926), que optaba por la compactación y la combinación de viviendas unifamiliares y colectivas, o el fraccionamiento "Lomas de Chapultepec" (1928-29), inspirado en la Ciudad Jardín, ambos del arquitecto José Luis Cuevas. Por otro lado, el primer intento de ordenación funcionalista a escala metropolitana tiene lugar en 1933, cuando el arquitecto Carlos Contreras intenta promover el "Plano Regulador del Distrito Federal".

7 Meyer ya había aplicado estos conceptos en Basilea, donde utilizó el principio del Coop en el conjunto de 150 viviendas Freidorf Siedlung (1914-1924). Bajo este principio, la arquitectura se entendía como un bien colectivo fruto del cooperativismo social de todos los agentes implicados y los proyectos debían plantear programas funcionales cooperativistas para los usuarios una vez entregados a la sociedad.

8 Arquitectos Mario Pani y Salvador Ortega.

9 Arquitectos Mario Pani y Luis Ramos Cunningham.

10 Arquitectos Alejandro Prieto Posadas y José María Gutiérrez Trujillo.

11 Arquitectos Mario Pani, Luis Ramos y Enrique Molinar.

12 Esta superficie está referida a las viviendas de interés social aunque también pueden encontrarse viviendas en desarrollos privados con esta superficie. De forma estándar, la superficie del lote es de 60 metros cuadrados contando con la superficie de estacionamiento aunque existen viviendas de interés social con la mitad de la superficie estándar.

13 Se estima que más de la mitad del tejido urbano de la Zona Metropolitana del Valle de México es de carácter informal o de autoconstrucción (Duhau y Giglia, 2008).

14 Castells, Manuel. 2004. "La era de la información: economía, sociedad y cultura". Madrid: siglo XXI, pág. 444.

\section{Referencias}

Arellano, Blanca, y Josep Roca. 2010. "El urban sprawl, ¿un fenómeno de alcance planetario?". Los ejemplos de México y España". ACE: Architecture, City and Environment, Vol. 4, 12, 115-148.

Augé, Marc. 1993. "Los no lugares: espacios del anonimato". Barcelona: Gedisa.

Borja, Jordi, y Zaida Muxí. 2003. "El espacio público: ciudad y ciudadanía". Barcelona: Electa.

Borja, Jordi. 2007. "Revolución y contrarrevolución en la ciudad global: las expectativas frustradas por la globalización de nuestras ciudades". Revista EURE, Vol. 33, 100, 35-50.

Castells, Manuel. 1986. "La ciudad y las masas. Sociología de los movimientos sociales urbanos". Madrid: Alianza.

Castells, Manuel. 2004. "La era de la información: economía, sociedad y cultura". Madrid: siglo XXI. 
Connolly, Priscilla. 2003. "Urban slums reports: the case of Mexico City, Mexico. Case study prepared for the United Nations Global Report on Human Settlements". Ciudad de México: Universidad Autónoma Metropolitana-Azcapotzalco.

Connolly, Priscilla. 2012. "La urbanización irregular y el orden urbano en la Zona Metropolitana del Valle de México de 1990 a 2005". En Clara Salazar (ed.), Irregular: Suelo y mercado en América Latina, 379425. México: El Colegio de México.

De Mattos, Carlos. 2006. "Modernización capitalista y transformación metropolitana en América Latina: cinco tendencias constitutivas". Geraiges de Lemos, A. et. al. América Latina, cidade, campo e turismo, 41-73. San Pablo: CLACSO.

De Solá-Morales. 1997. "Las formas de crecimiento urbano". Barcelona: Edicions UPC.

Duhau, Emilio. 2003. "División social del espacio metropolitano y movilidad residencial". Papeles de Población, vol. 9, (36), 161-210.

Duhau, Emilio, y Angela Giglia. 2008. "Las reglas del desorden: habitar la metrópoli". México: UAM-Azcapotzalco, Siglo xxi.

Galster, George, et al. 2011. "Wrestling sprawl to the ground: defining and measuring an elusive concept." Housing policy debate, vol.12, (4), 681-717.

Garay Arellano, Graciela. 2004. "Modernidad habitada: Multifamiliar Miguel Alemán, ciudad de México, 1949-1999”. Ciudad de México: Instituto de Investigaciones Dr. Jose Maria Luis Mora.

Garcés-Fierros, César. 2009. "Suelo urbano para la población pobre de México. En La situación demográfica de México". Ciudad de México: Consejo Nacional de Población, $87-102$.

Garza, Gustavo. 2015. "Valor de los medios de consumo colectivo en la ciudad de México". México: El Colegio de Mexico AC.

Fishman, Robert. 1987. "Bourgeois utopias: The rise and fall of Suburbia". New York: Basic Books.

Fulton, William B., et al. 2001. "Who sprawls most?: How growth patterns differ across the US". Washington, DC: Brookings Institution,
Center on Urban and Metropolitan Policy.

XIII Censo de población y vivienda. 2010. Instituto Nacional de Estadística y Geografía (INEGI). Aguascalientes: Inegi.

Jackson, Kenneth T. 1985. "Crabgrass frontier: The suburbanization of the United States". New York: Oxford University Press.

Lefebvre, Henri. 1968. "Le droit à la ville". París: Editions Antrhopos.

Lindón, Alicia. "La casa bunker y la deconstrucción de la ciudad". Liminar, 2006, vol. 4, (2), 18-35.

Monkkonen, Paavo. 2011. "The housing transition in Mexico: Expanding access to housing finance". Urban Affairs Review, vol. 47, (5), 672-695.

Nogué, Joan. 2007. "La construcción social del paisaje". Madrid: Biblioteca Nueva.

Nogué, Joan. 2008. "Territorios sin discurso, paisajes sin imaginario: retos y dilemas". Ería: Revista cuatrimestral de geografía, (73-74), 373-382.

Sánchez, Landy, y Clara Salazar. 2011. "Lo que dicen las viviendas deshabitadas sobre el censo de población 2010". Coyuntura demográfica, 2011, vol. 1, p. 66-72.

Rodríguez, Jorge y Camilo Arriagada. 2004. "Segregación residencial en la ciudad latinoamericana". Revista Eure, vol. 30, (89), 05-24.

Sabatini, Francisco. 2006. "La segregación social del espacio en las ciudades de América Latina". Washington, D.C: Inter-American Development Bank.

Sassen, Saskia. 2007. "El reposicionamiento de las ciudades y regiones urbanas en una economía global: ampliando las opciones de políticas y gobernanza". Revista Eure, Vol. 33, (100), 9-34.

Schteingart, Martha. 1989. "Los productores del espacio habitable: Estado, empresa y sociedad en la Ciudad de México". México: El Colegio de México.

Soja, Edward W. 2000. "Postmetropolis: critical studies of cities and regions". Oxford: Blackwell. 